\title{
Difference In The Topological Organization of White Matter Structural Connectome Between Methamphetamine and Heroin Use Disorder
}

\section{Wei Li}

Tangdu Hospital, Air Force Medical University

\section{Lei Wang}

Tangdu Hospital, Air Force Medical University

Zhuomin Lyu

Tangdu Hospital, Air Force Medical University

Jiajie Chen

Tangdu Hospital, Air Force Medical University

\section{Yichen Sun}

Tangdu Hospital, Air Force Medical University

Jia Zhu

Tangdu Hospital, Air Force Medical University

\section{Wei Wang}

Tangdu Hospital, Air Force Medical University

\section{Yarong Wang}

The First Affiliated Hospital of Xi'an Jiaotong University

Qiang Li (D357492329@qq.com)

Tangdu Hospital, Air Force Medical University

\section{Research Article}

Keywords: Heroin use disorder, Methamphetamine use disorder, Diffusion tensor imaging, Structural connectome

Posted Date: April 15th, 2021

DOI: https://doi.org/10.21203/rs.3.rs-413172/v1

License: (1) (1) This work is licensed under a Creative Commons Attribution 4.0 International License. Read Full License 
Version of Record: A version of this preprint was published at Behavioural Brain Research on January 1st, 2022. See the published version at https://doi.org/10.1016/j.bbr.2022.113752. 


\section{Abstract}

Background: Both methamphetamine use disorder (MAUD) and heroin use disorder (HUD) were related to the activation of the dopamine transmission, while the psychological symptoms caused by HUD and MAUD were significantly different. The topological organization of structural connection that may underlie these differences remains unknown.

Methods: Demographic matched 23 male MAUD patients, 20 HUD patients, and 21 healthy controls (HC) participated in the analysis. Diffusion tensor imaging and probabilistic tractography were used for white matter network construction. Psychological symptoms were evaluated by the Symptom Checklist-90. Differences of graph-level and nodal-level properties among groups were explored. The network Hubs distribution and the relationship between the network alteration and psychological status were identified.

Results: MAUD patients demonstrated significantly increased scores in anxiety, hostility, and schizophrenia nuclear symptoms. HUD group showed significantly increased global efficiency and network strength than HC and increased network strength than MAUD. Compared with HUD, the MAUD group showed significantly decreased nodal strength and efficiency distributed mainly in the temporal, parietal and occipital regions. We also found the network Hubs were decreased in MAUD group but increased in HUD group. The nodal strength in right superior temporal gyrus was significantly correlated with the psychological scores in MAUD patients.

Conclusion: These findings reflect the significant differences in topological structural connection between HUD and MAUD patients. These pieces of evidences help shed some light on the neurobiological mechanisms of the psychological difference between HUD and MAUD, and extend our understanding of the structural disruption underline the MAUD related psychological symptoms.

\section{Background}

Drug use disorder was defined by Diagnostic and Statistical Manual Disorders 5th edition (DSM-5) as a chronically relapsing brain disorder and characterized by compulsive drug seeking and taking despite serious negative consequences, and the emergence of a negative emotional state during withdrawal [1]. According to the 2019 World Drug Report and Annual Report on Drug Control in China, about 270 million people worldwide use drugs each year, methamphetamine (MA) is the most abused drug in China and the second across the globe. MA and heroin are primary abused drugs in China, 55.2\% MA use disorder (MAUD) and $37.5 \%$ heroin use disorder (HUD) in all of the drug abuse. Both MAUD and HUD can result in direct health consequences and secondary social costs, such as violent behavior and drug-related crime, which gained attention as a serious public health concern.

Although most drug addiction is related to the activation of the dopamine transmission, the mechanisms can be different depending on the drug class [2]. MA, heroin, cocaine, cannabis, alcohol and sedatives have all been implicated in substance induced psychosis [3], while the psychological symptoms caused by HUD and MAUD are significantly different. HUD can result in obvious physical symptoms and reduced 
willpower [4], but MAUD usually caused schizophrenia-like symptoms, such as anxiety, depression, delusion, hallucination and hostility $[5,6]$. However, the underlying neuromechanism of these psychological symptoms related to HUD and MAUD was still unclear, and there is no governmentapproved medication to treat MAUD, the existing psychological interventions need much improvement in efficacy[7]. Identify the difference of structural and functional alteration between HUD and MAUD and the relationship with the psychological symptoms may useful for improving the strategy of MAUD treatment.

Neuroimaging research has advanced our understanding of the neurobiological mechanism of drug use disorder and psychotic disorder. Diffusion tensor imaging (DTI) is a non-invasive neuroimaging technique that can provide relative quantitative measurement for investigating the pathological characteristics of white matter microstructure by measuring the random movement of water molecules in neural tissue [8]. A few DTI studies have reported abnormal white matter integrity in HUD and MAUD patients. Decreased white matter integrity were reported in HUD patients in specific brain regions, such as corpus callosum, frontal white matter, temporal white matter, thalamic radiation, superior and inferior longitudinal fasciculi, cerebellar, and cingulate gyrus [9-12]. Regional white matter deficits in HUD patients appear to implicate damage to tracts connecting cortico-limbic-striatal regions, specifically the cingulum and the short range fibers of the superior longitudinal fasciculus were reported by a meta-analysis [13]. MAUD patients showed persistent microstructure deficits of white matter surrounding the basal ganglia [14], decreased white matter integrity in anterior callosal and prefrontal white matter [15-18], and even globally diminished white matter integrity [19]. However, most of the previous studies were based on the voxelwised or tract-based methods, only detecting the alterations in some specified regions or white matter tracts. As been identified by previous studies, the human brain is a highly complex and interconnected network, balancing the regional segregation and special information integration [20].

Graph theory enables analyses of the whole brain efficiency of information processing and specific network properties [21]. The white matter connectivity can reflect the integration of the brain structure, but only a few network-based studies focus on the alteration of the white matter network organization in drug use disorders. Sun et al. found that HUD patients had widespread abnormalities in structural connectivity, including the default-mode, attentional and visual systems, and the non-planning impulsivity was negatively correlated with the increase in the connection strength within-temporal [22]. Zhang et al. found significantly increased connections were located in the paralimbic, orbitofrontal, prefrontal and temporal regions [23]. In our previous resting functional magnetic resonance imaging (MRI) study, we found that MAUD patients had increased brain activity in the thalamus, right inferior temporal gyrus and bilateral postcentral gyrus, and decreased brain activity in the cerebellum and left middle frontal gyrus [24], but the structural basis of these functional network changes was still unclear. The alterations in structural brain connections may underlie the functional and psychological difference between HUD and MAUD patients, while the whole-system-level of the understanding was still lacking.

A deeper understanding of neurobiological determinants of global structure integration/segregation may thus have promising clinical implications, including the identification of potential new biomarkers and therapeutic targets [20]. Therefore, the present study aimed to identify the difference in the topological 
organization of white matter structural connectome between MAUD and HUD patients, and identify the relationship to the psychological symptoms. We hypothesized that there are significant differences in global and regional characteristics of white matter network between MAUD and HUD patients, the specific white matter network properties of MAUD are related to their psychological symptoms.

\section{Methods}

\section{Ethics statement}

The present study was approved by the Institutional Board of Tangdu Hospital, Air Force Medical University, Xi'an (Number: TDLL-2017008). All participants were informed of the research content in advance and sighed informed consent. All methods were performed in accordance with the Declaration of Helsinki.

\section{Participants}

Twenty-five male MAUD and 25 male HUD patients were recruited from the community in Xi'an, Shaanxi, China. Twenty-one demographically matched male healthy controls $(\mathrm{HC})$ were recruited from the same community. The inclusion criteria for drug use disorders were as follows: (1) aged 18-50 years old; (2) meeting the diagnostic criteria for substance use disorder in the DSM-5; (3) MA or heroin use duration longer than 12 months and no history of mixed drug abuse; (4) being strongly right-handed as judged by the Edinburgh handedness inventory. The inclusion criteria for $\mathrm{HC}$ were the same as the drug use disorder patients except for the items for drug use. Exclusion criteria for all participants were (1) history of craniocerebral trauma or neurological disease and/or neurological signs; (2) any current medical illness; (3) daily consumption of alcohol; (4) claustrophobia or any MRI contraindications. All the participants in present study were cigarette smokers.

\section{Psychological evaluation}

The Symptom Checklist-90 (SCL-90) was used for the evaluation of self-reported psychological status in all participants under the guidance of physicians before MRI scanning. The rating scale consisted of 10 categories and grouped along nine symptom dimensions reflecting broad psychological symptom status, include somatization, obsession-compulsion, interpersonal sensitivity, depression, anxiety, hostility, terror, paranoid, and psychoticism [25]. Schizophrenia nuclear symptoms dimension was adopted, which obtained adding the four items $(7,16,35$ and 62$)$ of the SCL-90, represent delusions of control, auditory hallucinations, thought-broadcasting and thought-intrusion [25], it brings together milder versions of the core diagnostic symptoms of psychosis $[25,26]$.

\section{Image acquisition}

Imaging data was acquired on a 3.0T GE Signa Excite HD whole-body MRI system in Tangdu hospital, with a gradient strength of $40 \mathrm{mT} / \mathrm{m}$, a slew rate of $150 \mathrm{~T} / \mathrm{m} / \mathrm{sec}$, and an eight-channel head coil (GE Medical Systems, Milwaukee, WI, USA). Foam padding was used to minimize the head movement and ear 
plugs were used to reduce the noise. A routine $T_{2}$-weighted imaging was collected to obviate the gross structure abnormalities. DTI data were collected using a spin-echo echo-planar sequence, the parameters were as follows: repetition time $=7600 \mathrm{~ms}$, echo time $=61.5 \mathrm{~ms}$, number of gradient orientations $=25$, matrix $=128 \times 128$, field of view $=24 \times 24 \mathrm{~cm}$, number of excitations=2, slice thickness $=4 \mathrm{~mm}$ with no gap, and $b$ value $=1000 \mathrm{~s} / \mathrm{mm}^{2}$. The total scanning time for each participant took about $10 \mathrm{~min}$.

\section{DTI data processing}

The image data were processed using FSL6.0 (https://fsl.fmrib.ox.ac.uk/). Head motion and image distortions induced by eddy currents were corrected by eddy package in FSL[27]. Bayesian estimation of diffusion parameters obtained using sampling (bedpostx) and probabilistic tractography (probtrackx) techniques were used to generate white matter connectivity network[28]. The parameter for bedpostx method was set as the toolbox's default. For probtrackx method, parameters were: the number of samples was 5000 per voxel, curvature threshold set at 0.2, with loop-check option on[29]. A total of 90 cortical regions were defined as regions of interest (ROI) using the AAL90 atlas and warped into individual diffusion space for each subject. These ROls were used as waypoint and termination masks when running probtrackx in network-mode. To accelerate the calculation process, we used the graphics processing units version of bedpostx and probtrackx[30, 31].

This network mode probabilistic tractography calculates a $90 \times 90$ connectivity matrix, in which the value of each element represents the number of streamlines connecting two corresponding ROIs. These matrices were then normalized to eliminate the differences in the seed-ROI sizes, through dividing each row of the matrix for the corresponding waytotal number. In this way, an anatomical connectivity index was obtained for each reconstructed tract, which is an indirect measure of tract integrity.

To explore the network properties of the whole cortex, a bunch of the graph metrics were calculated using the brainGraph package in $\mathrm{R}$ (https://github.com/cwatson/brainGraph), including the graph-level metrics

(network strength $\left(S_{p}\right)$ and global efficiency $\left(E_{\text {glob }}\right)$ ), and the nodal-level metrics (nodal strength and nodal efficiency $\left(E_{n o d}\right)$ ). Applying graph analysis to normalized connectivity matrices requires the choice of a specific connection density. The influence of inter-subject variability in the total number of reconstructed streamlines should be considered. In this work, we adopted both "subject" threshold and "matrix" threshold, the same as previous publications[32,33]. The "subject" threshold was chosen to only accept connections which are present in at least $50 \%$ of the subjects of a given group, thus reducing the individual anatomy influences. The "matrix" threshold was chosen over a range of probability values from 0.001 to 0.01 [33]. To reduce the risk of erroneous discoveries due to the presence of spurious connections, a strict threshold of 0.01 was chosen for subsequent graph-level and nodal-level metrics calculations.

\section{Statistical analyses}

One-way ANOVA was used for demographic characteristics and psychiatric symptoms evaluations using SPSS 19.0 software. To determine the group differences in graph-level and nodal-level metrics, the 
general linear models (GLMs) were performed using brainGraph. Partial correlation analysis was conducted in MAUD patients between the SCL-90 scores and the graph/nodal metrics, performed by SPSS 19.0 software, using age, education and cigarettes smoked per day as covariates. All statistical results were corrected for multiple comparisons using the false discovery rates (FDR) method if needed. The statistical significance was set as $P<0.05$ in all analyses.

\section{Results}

\section{Demographic and clinical characteristics}

Five participants (2 MAUD and 5 HUD) were excluded due to the gross structure abnormalities in $\mathrm{T}_{2} \mathrm{Wl}$ images or head movement. Finally, 23 MAUD, 20 HUD, and $21 \mathrm{HC}$ participated in the analyses. No significant differences were found in age, education level, and cigarette smoke among groups. The duration of drug abuse between MAUD and HUD had no significantly different, but the dosage of heroin use in HUD was significantly higher than MA use in MAUD patients (Table 1).

Table 1

Demographic and clinical characteristics of participants (mean \pm S.D.)

\begin{tabular}{|c|c|c|c|c|}
\hline Characteristics & $\begin{array}{l}\text { MAUD } \\
(n=23)\end{array}$ & $\begin{array}{l}\text { HUD } \\
(n=20)\end{array}$ & $\begin{array}{l}\mathrm{HC} \\
(n=21)\end{array}$ & $\begin{array}{l}P \text { value } \\
\text { from ANOVA } \\
\text { Two-sample T- } \\
\text { test }\end{array}$ \\
\hline Age (years) & $28.26 \pm 5.08$ & $31.50 \pm 7.84$ & $\begin{array}{l}31.48 \pm \\
7.05\end{array}$ & 0.189 \\
\hline Education level (years) & $9.39 \pm 2.23$ & $10.80 \pm 2.76$ & $\begin{array}{l}10.57 \pm \\
2.25\end{array}$ & 0.125 \\
\hline $\begin{array}{l}\text { Number of cigarettes (per } \\
\text { day) }\end{array}$ & $18.83 \pm 9.89$ & $17.25 \pm 4.99$ & $\begin{array}{l}14.05 \pm \\
6.82\end{array}$ & 0.119 \\
\hline $\begin{array}{l}\text { Duration of drug use } \\
\text { (months) }\end{array}$ & $30.30 \pm 18.55$ & $41.25 \pm 25.68$ & N.A. & 0.114 \\
\hline $\begin{array}{l}\text { Total dosage of drug use } \\
\text { (gram) }\end{array}$ & $\begin{array}{l}139.51 \pm \\
249.42\end{array}$ & $\begin{array}{l}863.62 \pm \\
567.74\end{array}$ & N.A. & $\square 0.001 *$ \\
\hline
\end{tabular}

\section{Psychological difference among groups}

There was significant difference in anxiety, hostility, and schizophrenia nuclear symptoms among the three groups. The MAUD patients showed higher score in anxiety, hostility, and schizophrenia nuclear symptoms compared with HC. The higher hostility score was found in MAUD patients compared with HUD (Table 2). 
Table 2

Mean scores and group comparison of SCL-90 (mean \pm S.D.)

\begin{tabular}{|c|c|c|c|c|c|c|c|}
\hline \multirow[t]{2}{*}{ Item } & \multicolumn{3}{|l|}{ Group } & \multirow{2}{*}{$\begin{array}{l}P \text { value } \\
\text { from } \\
\text { ANOVA }\end{array}$} & \multicolumn{3}{|c|}{ Multiple comparisons } \\
\hline & MAUD & HUD & $\mathrm{HC}$ & & $\begin{array}{l}\text { MAUD } \\
\text { vs HC }\end{array}$ & $\begin{array}{l}\text { HUD } \\
\text { vs HC }\end{array}$ & $\begin{array}{l}\text { MAUD vs } \\
\text { HUD }\end{array}$ \\
\hline Total average score & $\begin{array}{l}0.76 \pm \\
0.63\end{array}$ & $\begin{array}{l}0.55 \pm \\
0.30\end{array}$ & $\begin{array}{l}0.42 \pm \\
0.48\end{array}$ & 0.085 & N.A. & N.A. & N.A. \\
\hline Somatization & $\begin{array}{l}0.64 \pm \\
0.67\end{array}$ & $\begin{array}{l}0.45 \pm \\
0.30\end{array}$ & $\begin{array}{l}0.38 \pm \\
0.50\end{array}$ & 0.237 & N.A. & N.A. & N.A. \\
\hline Obsession-compulsion & $\begin{array}{l}0.92 \pm \\
0.75\end{array}$ & $\begin{array}{l}0.54 \pm \\
0.31\end{array}$ & $\begin{array}{l}0.57 \pm \\
0.63\end{array}$ & 0.092 & N.A. & N.A. & N.A. \\
\hline $\begin{array}{l}\text { Interpersonal } \\
\text { sensitivity }\end{array}$ & $\begin{array}{l}0.81 \pm \\
0.78\end{array}$ & $\begin{array}{l}0.64 \pm \\
0.38\end{array}$ & $\begin{array}{l}0.47 \pm \\
0.60\end{array}$ & 0.191 & N.A. & N.A. & N.A. \\
\hline Depression & $\begin{array}{l}0.79 \pm \\
0.68\end{array}$ & $\begin{array}{l}0.74 \pm \\
0.46\end{array}$ & $\begin{array}{l}0.45 \pm \\
0.57\end{array}$ & 0.180 & N.A. & N.A. & N.A. \\
\hline Anxiety & $\begin{array}{l}0.73 \pm \\
0.68\end{array}$ & $\begin{array}{l}0.51 \pm \\
0.37\end{array}$ & $\begin{array}{l}0.30 \pm \\
0.41\end{array}$ & $0.029 *$ & $0.008^{\star}$ & 0.202 & 0.172 \\
\hline Hostility & $\begin{array}{l}1.16 \pm \\
1.05\end{array}$ & $\begin{array}{l}0.53 \pm \\
0.53\end{array}$ & $\begin{array}{l}0.62 \pm \\
0.85\end{array}$ & $0.036^{\star}$ & $0.039 *$ & 0.754 & $0.019 *$ \\
\hline Terror & $\begin{array}{l}0.42 \pm \\
0.58\end{array}$ & $\begin{array}{l}0.28 \pm \\
0.26\end{array}$ & $\begin{array}{l}0.22 \pm \\
0.32\end{array}$ & 0.289 & N.A. & N.A. & N.A. \\
\hline Paranoid & $\begin{array}{l}0.86 \pm \\
0.94\end{array}$ & $\begin{array}{l}0.46 \pm \\
0.37\end{array}$ & $\begin{array}{l}0.41 \pm \\
0.52\end{array}$ & 0.053 & N.A. & N.A. & N.A. \\
\hline Psychoticism & $\begin{array}{l}0.55 \pm \\
0.62\end{array}$ & $\begin{array}{l}0.50 \pm \\
0.34\end{array}$ & $\begin{array}{l}0.42 \pm \\
0.48\end{array}$ & 0.689 & N.A. & N.A. & N.A. \\
\hline Additional items & $\begin{array}{l}0.82 \pm \\
0.67\end{array}$ & $\begin{array}{l}0.80 \pm \\
0.42\end{array}$ & $\begin{array}{l}0.43 \pm \\
0.52\end{array}$ & $0.043^{*}$ & $0.023^{*}$ & $0.038^{*}$ & 0.895 \\
\hline $\begin{array}{l}\text { Schizophrenia nuclear } \\
\text { symptoms }\end{array}$ & $\begin{array}{l}0.65 \pm \\
0.68\end{array}$ & $\begin{array}{l}0.38 \pm \\
0.28\end{array}$ & $\begin{array}{l}0.23 \pm \\
0.28\end{array}$ & $0.011^{\star}$ & $0.003^{\star}$ & 0.310 & 0.053 \\
\hline
\end{tabular}

\section{Group difference in Graph-level network organization}

Within the scope of the global network, drug use disorder patients presented increased $\mathrm{S}_{\mathrm{p}}$ than $\mathrm{HC}$, after corrected by FDR, only HUD group showed significantly increase $S_{\mathrm{p}}$ than $\mathrm{HC}(t=3.66, P=0.0005)$, there was no significant difference between MAUD and HC. When compared with MAUD, the HUD group showed significantly increased $\mathrm{S}_{\mathrm{p}}(t=-2.31, P=0.024)$. Meanwhile, HUD group showed significantly increased $\mathrm{E}_{\text {glob }}$ than $\mathrm{HC}(t=2.09, P=0.041)$. There was no significant difference between MAUD and HUD or between MAUD and $\mathrm{HC}$ in $\mathrm{E}_{\text {glob }}$ (Figure. 1). 


\section{Group difference in Nodal-level properties}

In the nodal-level network measures, HUD group had significantly increased nodal strength and $E_{\text {nod }}$ compared with $\mathrm{HC}$ group, distributed mainly in the frontal, occipital, and temporal regions. Compared with the HUD group, MAUD group showed significantly decreased nodal strength and $\mathrm{E}_{\text {nod }}$ distributed mainly in the temporal, parietal and occipital regions (Table 3 and Table 4). 
Table 3

Brain regions with significant difference in Nodal Strength

\begin{tabular}{|c|c|c|c|c|}
\hline Comparisons & Regions & Hemisphere & $t$ & $P$ value \\
\hline \multirow[t]{5}{*}{ HUD『HC } & Cuneus & L & 3.29 & $0.030 *$ \\
\hline & Lingual & $\mathrm{R}$ & 3.71 & $0.010^{*}$ \\
\hline & Inferior Occipital gyrus & $\mathrm{R}$ & 3.75 & $0.010^{*}$ \\
\hline & Fusiform & L & 4.91 & $0.001 *$ \\
\hline & SupraMarginal & L & 3.77 & $0.010^{\star}$ \\
\hline MAUD®HC & Anterior Cingulum & L & 3.66 & $0.048^{*}$ \\
\hline \multirow[t]{15}{*}{ HUD囚MAUD } & Rolandic Operculum & $\mathrm{R}$ & -3.09 & $0.021^{*}$ \\
\hline & Middle Cingulum & L & -3.43 & $0.009 *$ \\
\hline & Lingual & L & -3.42 & $0.009 *$ \\
\hline & Lingual & $\mathrm{R}$ & -3.46 & $0.009 *$ \\
\hline & Inferior Occipital gyrus & L & -4.39 & $0.001 *$ \\
\hline & Inferior Occipital gyrus & $\mathrm{R}$ & -3.88 & $0.005^{\star}$ \\
\hline & Fusiform & L & -3.73 & $0.006^{*}$ \\
\hline & Superior parietal gyrus & $\mathrm{R}$ & -4.46 & $0.001 *$ \\
\hline & Inferior Parietal gyrus & $\mathrm{R}$ & -3.19 & $0.017^{*}$ \\
\hline & SupraMarginal & $\mathrm{R}$ & -3.93 & $0.005^{\star}$ \\
\hline & Paracentral Lobule & L & -3.65 & $0.006^{*}$ \\
\hline & Superior temporal gyrus & L & -2.83 & $0.037^{*}$ \\
\hline & Superior temporal gyrus & $\mathrm{R}$ & -5.07 & $0.000 *$ \\
\hline & Middle Temporal gyrus & L & -2.88 & $0.036^{*}$ \\
\hline & Middle Temporal gyrus & $\mathrm{R}$ & -3.73 & $0.006^{*}$ \\
\hline
\end{tabular}


Table 4

Brain regions with significant difference in $E_{\text {nod }}$

\begin{tabular}{|c|c|c|c|c|}
\hline Comparisons & Regions & Hemisphere & $t$ & $P$ value \\
\hline & Middle Frontal gyrus & $\mathrm{R}$ & 3.08 & $0.046^{*}$ \\
\hline \multirow[t]{5}{*}{ HUD®HC } & Lingual & $\mathrm{R}$ & 3.79 & $0.016^{*}$ \\
\hline & Fusiform & L & 4.18 & $0.008^{*}$ \\
\hline & Fusiform & $\mathrm{R}$ & 3.36 & $0.030 *$ \\
\hline & Middle Temporal gyrus & L & 3.08 & $0.046^{*}$ \\
\hline & Inferior Temporal gyrus & L & 3.38 & $0.030 *$ \\
\hline HUD囚MAUD & Superior temporal gyrus & $\mathrm{R}$ & -4.08 & $0.012^{*}$ \\
\hline
\end{tabular}

Hubs distribution

Nine network Hubs were identified in $\mathrm{HC}$ group, including the bilateral post cingulum, precuneus, cuneus, right dorsal superior frontal cortex, right supplementary motor area, and right calcarine. Right supplementary motor area and right calcarine turn to non-Hubs in MAUD patients compared with HC. While HUD group had increased Hubs distributed in the right middle frontal cortex, left middle cingulate, and right paracentral lobule compared with HC (Figure. 2).

\section{Correlation between network metrics and clinical variables}

At the graph-level, neither of the $S_{p}$ nor the $E_{g l o b}$ was significantly correlated with the demographic and SCL-90 in any drug use disorder group. At the nodal-level, nodal strength in the right superior temporal gyrus in the MAUD group was positively correlated with total average score of SCL-90, depression, anxiety, hostile, paranoid, and psychoticism score (Figure. 3). No correlation was found in $E_{\text {nod }}$ and SCL90 score.

\section{Discussion}

In the present study, we investigated the difference in the topological organization of white matter networks between MAUD and HUD patients. The major findings are as follows:(1) MAUD patients demonstrated significantly increased anxiety, hostility, and schizophrenia nuclear symptoms score. (2) HUD patients showed significantly increased $S_{p}$ and $E_{g l o b}$ than $H C$, and significantly increased $S_{p}$ than MAUD. (3) MAUD patients had significantly decreased nodal strength and $E_{\text {nod }}$ than HUD. (4)Compared with HC, MAUD had reduced Hubs, while HUD had increased Hubs. (5) Nodal strength in the right superior temporal gyrus was positively correlated with the psychological scores in MAUD patients. These findings 
enhanced our understanding of the potential neurobiological foundation underlying the difference of psychological symptoms between MAUD and HUD patients.

The most important behavioral effects of MA are the mood-altering properties. Psychosis is indued more commonly by MA than by any other stimulants, perhaps because of the longer duration of action produced by MA when compared with the shorter half-life of other stimulants [34]. In this study, we found significantly increased scores in anxiety, hostility, and schizophrenia nuclear symptoms in MAUD patients. The hostility score in MAUD was higher than HUD. These findings are consistent with the previous. After large doses or/and long-term abuse, MAUD patients may experience violent behavior than any other psychoactive drugs, and they had higher scores on affective and positive symptoms, such as hostility, anxiety, depression and hallucinations [35].

The strength of a network $\left(S_{p}\right)$ is the average of the strength across all of the nodes in the network [22]. $S_{p}$ is related to the connection density or the "wiring cost" of the brain networks, the larger of the $S_{p}$, the more expensive of the "wiring cost" of the network [23]. $E_{\text {glob }}$ is defined as the average of efficiency for all node pairs, measures the global efficiency of parallel information transfer in the network [36]. Several graph theoretic studies have revealed abnormal topological organization of structural networks in HUD patients. Zhang et al. found HUD patients showed significantly increased $\mathrm{E}_{\mathrm{glob}}$ and $\mathrm{S}_{\mathrm{p}}$ compared with $\mathrm{HC}$ [23], which is consistent with the present study. Increased $S_{p}$ and $E_{g l o b}$ means increased global integration, this may indicate that the white matter networks in HUD patients may keep high "wiring cost" or break up the trade-off between the efficiency and cost and may shift towards a random network [23]. However, there is an inconsistent finding in Sun's study, they found no significant differences in any global parameter of the whole brain white matter networks between HUD and HC [22]. This may be caused by the abstinent from heroin use of their HUD patients, the functional and structural recovery during heroin abstinence had been identified in our previous studies [37-39].

Increased positive symptoms score in stimulant-induced psychosis were believed to reflect the dysregulation of the mesolimbic dopamine pathway [40,41], and which may be mediated by frontal, striatal and limbic regions [42]. In this study, we found significantly increased positive symptoms in MAUD patients present as increased schizophrenia nuclear symptoms score. Meanwhile, MAUD group showed significantly decreased nodal strength and $E_{\text {nod }}$ in cingulum, parietal, temporal, and occipital regions than HUD. Decreased nodal strength and $E_{\text {nod }}$ in these regions may imply that the essentiality of these brain regions and the information transformation in the network were decreased. The significant correlation between the nodal strength in the right superior temporal gyrus and the psychological scores may indicate the essential function of the temporal cortices or limbic related regions underlying the MAUD related psychological symptoms.

The role of the parietal cortices in the development of psychological symptoms in schizophrenia has been established previously, and especially in the role of monitoring of internally generated thoughts and actions $[43,44]$. And this abnormal self-monitoring has been proposed as the neural basis for hallucinations and delusions [45]. Reduced nodal strength in parietal regions may play an important role 
in the higher incidence of hallucinations and delusions in MAUD patients. A role for parietal cortices may be an early-onset risk factor for both MAUD and schizophrenia [7]. And it has been reported that the gray matter atrophy would begin in the parietal cortices and progress to the temporal and finally the frontal cortices accompany by the progress of schizophrenia $[44,46]$. We found significantly decreased nodal strength and $E_{\text {nod }}$ in extensive temporal and parietal regions in MAUD patients when compared with HUD. The previous study has also found the smaller volume in left parietal/temporal lobe in schizophrenia patients with concurrent stimulant dependence [41], reduced gray matter in the parietal cortices in MAUD patients [47]. The disconnection within the parietal, temporal and occipital regions or with other regions, may be related to the abnormal neural response to visual and/or auditory stimuli in MAUD patients [48].

On the contrary, we found HUD patients have significantly increased nodal strength and $E_{\text {nod }}$ in some frontal, temporal and occipital regions compared with $\mathrm{HC}$. Which was similar with the previous studies. Zhang et al. found significantly increased $E_{\text {nod }}$ in the frontal regions, altered white matter connectivity in frontal regions may lead to the reduced cognitive control on craving and motivation in heroin users [23, 49]. Another study found increased structural connectivity within the DMN, attentional and visual systems, and specific within-frontal and within-temporal connections were significantly correlated with the heroin dosage and the non-planning impulsivity in HUD patients [22]. These findings may reveal the topological characteristic of heroin related white matter structure connectivity alterations, and suggested a potential neural-foundation of heroin caused craving and cognitive impairment.

The regions with high centrality values are structural cores of the brain and usually defined as Hubs [50], which plays a particularly important role toward integrating information across the system by accessing different modules. Brain Hubs are central to brain disorders in general [51]. The largest declines in function may occur when disease impinges on a Hub regions [52]. In the present study, nine Hubs were identified in $\mathrm{HC}$ group, the result was similar with previous studies [50]. We found two brain regions located in right supplementary motor area (SMA) and right calcarine turn into nonHubs in MAUD group. Network Hub has been considered important in how a disease spreads in a network [53]. We speculate that the loss of Hubs in the medial frontal and visual regions in MAUD patients may mean the originally disconnected in the network. Interestingly, we found three Hubs specific to HUD patients located in the right middle frontal cortex, left middle cingulum and right paracentral lobule. Increased Hubs in frontal/parietal regions was accompanied by increased nodal strength and $E_{\text {nod }}$ in these regions in HUD patients, these findings may relate to abnormally enhanced heroin craving and impaired function in cognition and decisions.

Some limitations should be noticed. Firstly, only males were included in this study, the potential gender related influence to the white matter network and the course of psychological symptoms were not identified. Studies found that females showed more rapid progression from initial drug use to MAUD, and female MAUD patients had smaller and thinner frontal cortices than males $[54,55]$. Female substances use disorder patients may experience a greater relative impact on the course of psychological symptoms than males [56]. Thus, further studies include the gender related influence should be considered. Secondly, the psychological evaluation is unspecific. More detailed evaluations such as the assessment 
of auditory and visual hallucinations as well as the positive and negative symptoms should be included in the future study. Thirdly, Future studies may be needed to investigate the relationship between the changes of structural network and functional network.

\section{Conclusions}

Taken together, our findings provide an interesting insight regarding the possible difference of white matter structure network between MAUD and HUD patients. The results showed that HUD patients had significantly increased $S_{p}$, $E_{g l o b}$ and increased nodal strength and $E_{n o d}$ in frontal, temporal and occipital regions, these may represent the abnormal structure connectivity caused by HUD. In particular, MAUD showed significantly decreased nodal strength and $E_{\text {nod }}$ in mesolimbic pathway, parietal, temporal, and occipital regions than HUD, these results may suggest the specific brain structure alterations caused by MAUD. These pieces of evidences help shed some light on the neurobiological mechanism of the psychological difference between HUD and MAUD, and extend our understanding of structural disruptions that underlie the MAUD related psychological symptoms.

\section{Abbreviations}

MAUD: Methamphetamine use disorder

HUD: Heroin use disorder

$\mathrm{HC}$ : Healthy controls

DSM-5: Diagnostic and Statistical Manual Disorders $5^{\text {th }}$

MA: Methamphetamine

DTI: Diffusion tensor imaging

MRI: Magnetic resonance imaging

SCL-90: Symptom Checklist-90

ROI: Regions of interest

$S_{p}:$ Network strength

$E_{\text {glob: }}$ Global efficiency

$E_{\text {nod }}$ : Nodal efficiency

GLMs: General linear models 
FDR: False discovery rates

SMA: Supplementary motor area

\section{Declarations}

\section{Ethics approval and consent to participate}

The present study was approved by the Institutional Board of Tangdu Hospital, Air Force Medical University, Xi'an (Number: TDLL-2017008). Informed consent was obtained.

\section{Consent for publication}

The manuscript was approved by all authors for publication.

\section{Availability of data and materials}

The datasets used during the current study are available from the corresponding author on reasonable request.

\section{Competing interests}

The authors report no biomedical financial interests or potential confilicts of interest.

\section{Funding}

This work was supported by grants from the National Natural Science Foundation of China (Nos. $81771813,82071497,81401393$, and 81671661$)$. The funding sponsors had no role in the design and conduct of the study.

\section{Authors' contributions}

W.L. , Q.L. and W.W. were responsible for the study design. J.J.C. and J.Z. contributed to the acquisition of MRI and demographical data. L.W. and Y.C.S. performed the data analysis. Y.R.W. and Z.M.L. assisted with data analysis and interpretation of findings. W.L. drafted the manuscript.

\section{Acknowledgements}

Not applicable.

\section{References}

1. Volkow ND, Koob GF, McLellan AT: Neurobiologic Advances from the Brain Disease Model of Addiction. N Engl J Med 2016, 374(4):363-371. 
2. Di Chiara G: Nucleus accumbens shell and core dopamine: differential role in behavior and addiction. Behav Brain Res 2002, 137(1-2):75-114.

3. Grant KM, LeVan TD, Wells SM, Li M, Stoltenberg SF, Gendelman HE, Carlo G, Bevins RA: Methamphetamine-associated psychosis. J Neuroimmune Pharmacol 2012, 7(1):113-139.

4. Blum J, Gerber H, Gerhard U, Schmid O, Petitjean S, Riecher-Rossler A, Wiesbeck GA, Borgwardt SJ, Walter M: Acute effects of heroin on emotions in heroin-dependent patients. Am J Addict 2013, 22(6):598-604.

5. Glasner-Edwards S, Mooney LJ: Methamphetamine psychosis: epidemiology and management. CNS Drugs 2014, 28(12):1115-1126.

6. Srisurapanont M, Ali R, Marsden J, Sunga A, Wada K, Monteiro M: Psychotic symptoms in methamphetamine psychotic in-patients. Int J Neuropsychopharmaco/ 2003, 6(4):347-352.

7. Guerin AA, Bonomo Y, Lawrence AJ, Baune BT, Nestler EJ, Rossell SL, Kim JH: Cognition and Related Neural Findings on Methamphetamine Use Disorder: Insights and Treatment Implications From Schizophrenia Research. Front Psychiatry 2019, 10:880.

8. Sexton CE, Mackay CE, Ebmeier KP: A systematic review of diffusion tensor imaging studies in affective disorders. Biol Psychiatry 2009, 66(9):814-823.

9. Li W, Li Q, Zhu J, Qin Y, Zheng Y, Chang H, Zhang D, Wang H, Wang L, Wang Y et al: White matter impairment in chronic heroin dependence: a quantitative DTI study. Brain Res 2013, 1531:58-64.

10. Bora E, Yucel M, Fornito A, Pantelis C, Harrison BJ, Cocchi L, Pell G, Lubman DI: White matter microstructure in opiate addiction. Addict Biol 2012, 17(1):141-148.

11. Qiu Y, Jiang G, Su H, Lv X, Zhang X, Tian J, Zhuo F: Progressive white matter microstructure damage in male chronic heroin dependent individuals: a DTI and TBSS study. PLoS One 2013, 8(5):e63212.

12. Lin WC, Chou KH, Chen CC, Huang CC, Chen HL, Lu CH, Li SH, Wang YL, Cheng YF, Lin CP: White matter abnormalities correlating with memory and depression in heroin users under methadone maintenance treatment. PLoS One 2012, 7(4):e33809.

13. Wollman SC, Alhassoon OM, Stern MJ, Hall MG, Rompogren J, Kimmel CL, Perez-Figueroa AM: White matter abnormalities in long-term heroin users: a preliminary neuroimaging meta-analysis. $\mathrm{Am} \mathrm{J}$ Drug Alcohol Abuse 2015, 41(2):133-138.

14. Zhuang W, Tang Y, Zhong N, Jiang H, Du J, Wang J, Zhao M: Persistent Microstructural Deficits of Internal Capsule in One-Year Abstinent Male Methamphetamine Users: a Longitudinal Diffusion Tensor Imaging Study. J Neuroimmune Pharmacol 2016, 11(3):523-530.

15. Salo R, Nordahl TE, Buonocore MH, Natsuaki Y, Waters C, Moore CD, Galloway GP, Leamon MH: Cognitive control and white matter callosal microstructure in methamphetaminedependent subjects: a diffusion tensor imaging study. Biol Psychiatry 2009, 65(2):122-128.

16. Kim IS, Kim YT, Song HJ, Lee JJ, Kwon DH, Lee HJ, Kim MN, Yoo DS, Chang Y: Reduced corpus callosum white matter microstructural integrity revealed by diffusion tensor eigenvalues in abstinent methamphetamine addicts. Neurotoxicology 2009, 30(2):209-213. 
17. Tobias MC, O'Neill J, Hudkins M, Bartzokis G, Dean AC, London ED: White-matter abnormalities in brain during early abstinence from methamphetamine abuse. Psychopharmacology (Berl) 2010, 209(1):13-24.

18. Lederer $K$, Fouche JP, Wilson D, Stein DJ, Uhlmann A: Frontal white matter changes and aggression in methamphetamine dependence. Metab Brain Dis 2016, 31(1):53-62.

19. Huang S, Yang W, Luo J, Yan C, Liu J: White Matter Abnormalities Based on TBSS and Its Correlation With Impulsivity Behavior of Methamphetamine Addicts. Front Psychiatry 2020, 11:452.

20. Lord LD, Stevner AB, Deco G, Kringelbach ML: Understanding principles of integration and segregation using whole-brain computational connectomics: implications for neuropsychiatric disorders. Philos Trans A Math Phys Eng Sci 2017, 375(2096).

21. Bullmore E, Sporns O: Complex brain networks: graph theoretical analysis of structural and functional systems. Nat Rev Neurosci 2009, 10(3):186-198.

22. Sun Y, Wang GB, Lin QX, Lu L, Shu N, Meng SQ, Wang J, Han HB, He Y, Shi J: Disrupted white matter structural connectivity in heroin abusers. Addict Biol 2017, 22(1):184-195.

23. Zhang R, Jiang G, Tian J, Qiu Y, Wen X, Zalesky A, Li M, Ma X, Wang J, Li S et al: Abnormal white matter structural networks characterize heroin-dependent individuals: a network analysis. Addict Biol 2016, 21(3):667-678.

24. Liu Y, Zhu J, Li Q, Wang YR, Li YB, Chen JJ, Dang S, Chen J, Shi H, Xue JH et al: Differences in the amplitude of low-frequency fluctuation between methamphetamine and heroin use disorder individuals: A resting-state fMRI study. Brain and Behavior 2020, 10(9).

25. Rossler W, Riecher-Rossler A, Angst J, Murray R, Gamma A, Eich D, van Os J, Gross VA: Psychotic experiences in the general population: a twenty-year prospective community study. Schizophr Res 2007, 92(1-3):1-14.

26. Zhornitsky S, Tikasz A, Rizkallah E, Chiasson JP, Potvin S: Psychopathology in Substance Use Disorder Patients with and without Substance-Induced Psychosis. J Addict 2015, 2015:843762.

27. Andersson JLR, Sotiropoulos SN: An integrated approach to correction for off-resonance effects and subject movement in diffusion MR imaging. Neuroimage 2016, 125:1063-1078.

28. Behrens TE, Berg HJ, Jbabdi S, Rushworth MF, Woolrich MW: Probabilistic diffusion tractography with multiple fibre orientations: What can we gain? Neuroimage 2007, 34(1):144-155.

29. Behrens TE, Woolrich MW, Jenkinson M, Johansen-Berg H, Nunes RG, Clare S, Matthews PM, Brady JM, Smith SM: Characterization and propagation of uncertainty in diffusion-weighted MR imaging. Magn Reson Med 2003, 50(5):1077-1088.

30. Hernandez M, Guerrero GD, Cecilia JM, Garcia JM, Inuggi A, Jbabdi S, Behrens TE, Sotiropoulos SN: Accelerating fibre orientation estimation from diffusion weighted magnetic resonance imaging using GPUs. PLoS One 2013, 8(4):e61892.

31. Hernandez-Fernandez M, Reguly I, Jbabdi S, Giles M, Smith S, Sotiropoulos SN: Using GPUs to accelerate computational diffusion MRI: From microstructure estimation to tractography and connectomes. Neuroimage 2019, 188:598-615. 
32. Watson CG, DeMaster D, Ewing-Cobbs L: Graph theory analysis of DTI tractography in children with traumatic injury. Neuroimage Clin 2019, 21:101673.

33. Watson CG, Stopp C, Newburger JW, Rivkin MJ: Graph theory analysis of cortical thickness networks in adolescents with d-transposition of the great arteries. Brain Behav 2018, 8(2):e00834.

34. Kleissl-Muir S, Raymond A, Rahman MA: Incidence and factors associated with substance abuse and patient-related violence in the emergency department: A literature review. Australas Emerg Care 2018, 21(4):159-170.

35. Panenka WJ, Procyshyn RM, Lecomte T, MacEwan GW, Flynn SW, Honer WG, Barr AM: Methamphetamine use: a comprehensive review of molecular, preclinical and clinical findings. Drug Alcohol Depend 2013, 129(3):167-179.

36. Tuladhar AM, van Uden IW, Rutten-Jacobs LC, Lawrence A, van der Holst $H$, van Norden A, de Laat K, van Dijk E, Claassen JA, Kessels RP et al: Structural network efficiency predicts conversion to dementia. Neurology 2016, 86(12):1112-1119.

37. Chen J, Wang F, Zhu J, Li Y, Liu W, Xue J, Shi H, Li W, Li Q, Wang W: Assessing effect of long-term abstinence on coupling of three core brain networks in male heroin addicts: A resting-state functional magnetic resonance imaging study. Addict Biol 2020:e12982.

38. Li Q, Wang Y, Zhang Y, Li W, Zhu J, Zheng Y, Chen J, Zhao L, Zhou Z, Liu Y et al: Assessing cueinduced brain response as a function of abstinence duration in heroin-dependent individuals: an event-related fMRI study. PLoS One 2013, 8(5):e62911.

39. Wei X, Chen J, Zhu J, Li Q, Li W, Wang W: Functional connectivity of posterior cingulate gyrus in heroin dependents treated by methadone maintenance and protracted abstinence measures: an event-related fMRI study. Brain Imaging and Behavior 2021.

40. Ujike H: Stimulant-induced psychosis and schizophrenia: the role of sensitization. Curr Psychiatry Rep 2002, 4(3):177-184.

41. Alexander PD, Gicas KM, Cheng A, Lang DJ, Procyshyn RM, Vertinsky AT, Panenka WJ, Thornton AE, Rauscher A, Wong JYX et al: A comparison of regional brain volumes and white matter connectivity in subjects with stimulant induced psychosis versus schizophrenia. Psychopharmacology (Berl) 2019, 236(12):3385-3399.

42. Hsieh JH, Stein DJ, Howells FM: The neurobiology of methamphetamine induced psychosis. Front Hum Neurosci 2014, 8:537.

43. Whitworth AB, Kemmler G, Honeder M, Kremser C, Felber S, Hausmann A, Walch T, Wanko C, Weiss $\mathrm{EM}$, Stuppaeck $\mathrm{CH}$ et al: Longitudinal volumetric MRI study in first- and multipleepisode male schizophrenia patients. Psychiatry Res 2005, 140(3):225-237.

44. Whitford TJ, Grieve SM, Farrow TF, Gomes L, Brennan J, Harris AW, Gordon E, Williams LM: Progressive grey matter atrophy over the first 2-3 years of illness in firstepisode schizophrenia: a tensor-based morphometry study. Neuroimage 2006, 32(2):511-519.

45. Frith C: The neural basis of hallucinations and delusions. CR Bio/ 2005, 328(2):169-175. 
46. Thompson PM, Vidal C, Giedd JN, Gochman P, Blumenthal J, Nicolson R, Toga AW, Rapoport JL: Mapping adolescent brain change reveals dynamic wave of accelerated gray matter loss in very early-onset schizophrenia. Proc Natl Acad Sci U S A 2001, 98(20):11650-11655.

47. Lyoo IK, Yoon S, Kim TS, Lim SM, Choi Y, Kim JE, Hwang J, Jeong HS, Cho HB, Chung YA et al: Predisposition to and effects of methamphetamine use on the adolescent brain. Mol Psychiatry 2015, 20(12):1516-1524.

48. Van Hedger K, Keedy SK, Schertz KE, Berman MG, de Wit H: Effects of methamphetamine on neural responses to visual stimuli. Psychopharmacology (Berl) 2019, 236(6):1741-1748.

49. Jasinska AJ, Stein EA, Kaiser J, Naumer MJ, Yalachkov Y: Factors modulating neural reactivity to drug cues in addiction: a survey of human neuroimaging studies. Neurosci Biobehav Rev 2014, 38:1-16.

50. Hagmann P, Cammoun L, Gigandet X, Meuli R, Honey CJ, Wedeen VJ, Sporns O: Mapping the structural core of human cerebral cortex. PLoS Biol 2008, 6(7):e159.

51. Crossley NA, Mechelli A, Scott J, Carletti F, Fox PT, McGuire P, Bullmore ET: The hubs of the human connectome are generally implicated in the anatomy of brain disorders. Brain 2014, 137(Pt 8):23822395.

52. Fornito A, Zalesky A, Breakspear M: The connectomics of brain disorders. Nat Rev Neurosci 2015, 16(3):159-172.

53. Kwon H, Choi YH, Seo SW, Lee JM: Scale-integrated Network Hubs of the White Matter Structural Network. Sci Rep 2017, 7(1):2449.

54. Hser YI, Evans E, Huang YC: Treatment outcomes among women and men methamphetamine abusers in California. J Subst Abuse Treat 2005, 28(1):77-85.

55. Kogachi S, Chang L, Alicata D, Cunningham E, Ernst T: Sex differences in impulsivity and brain morphometry in methamphetamine users. Brain Struct Funct 2017, 222(1):215-227.

56. Gearon JS, Bellack AS: Sex differences in illness presentation, course, and level of functioning in substance-abusing schizophrenia patients. Schizophr Res 2000, 43(1):65-70.

\section{Figures}



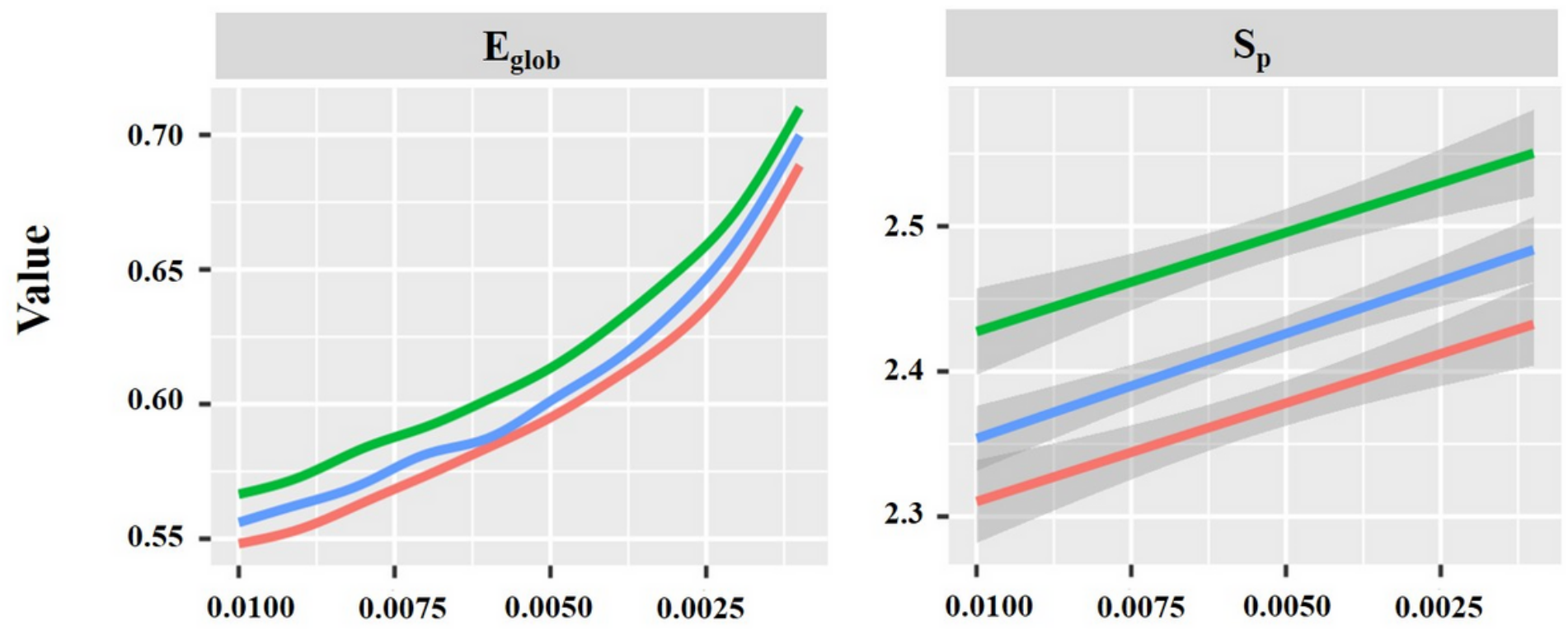

\section{Threshold}

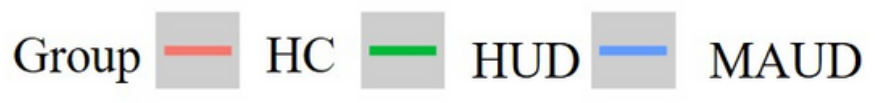

Figure 1

Network strength and global efficiency in HC, HUD, and MAUD groups. MAUD: methamphetamine use disorder; HUD: heroin use disorder; HC: healthy controls; Eglob: Global Efficiency; Sp: Network Strength.

Hubs in all groups

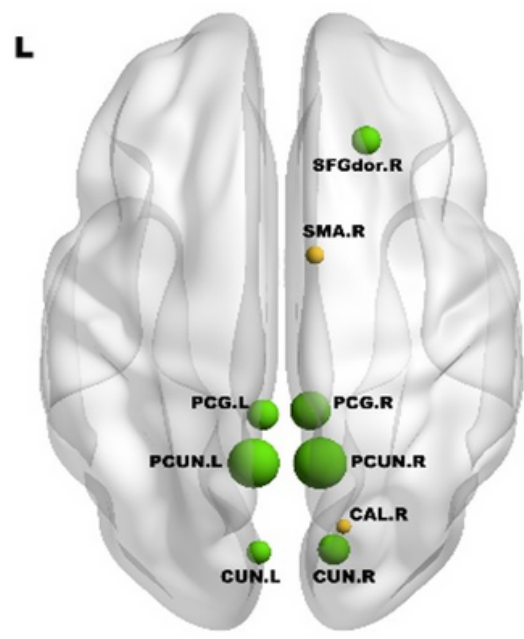

HC
Hubs in HUD and HC groups

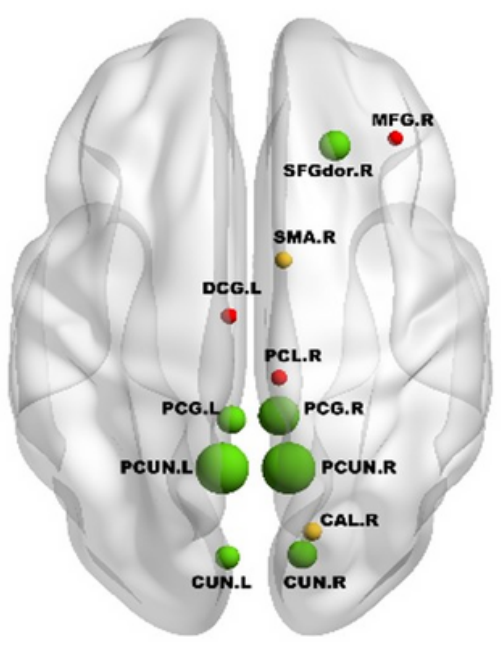

HUD
Hubs only in HUD groups

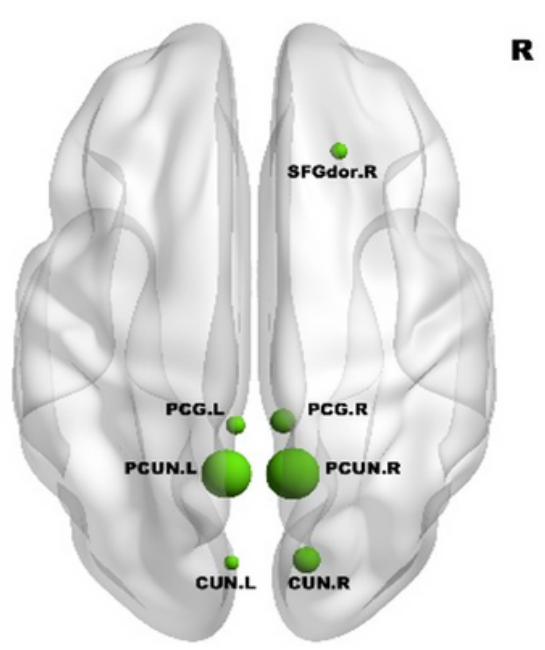

MAUD

Figure 2 
The Hubs distributions of the white matter network in HC, HUD, and MAUD groups. The size of the node indicates the value of weighted Enod, bigger means higher efficiency. CUN. L: left cuneus; CUN. R: right cuneus; PCUN.L: left precuneus; PCUN. R: right precuneus; PCG.L: left post cingulum; PCG.R: right post cingulum; CAL.R: right calcarine; SMA.R: right supplementary motor area; SFGdor. R: right dorsal superior frontal cortex; PCL. R: right paracentral lobule; DCG. L: left middle cingulate; MFG. R: right middle frontal cortex.
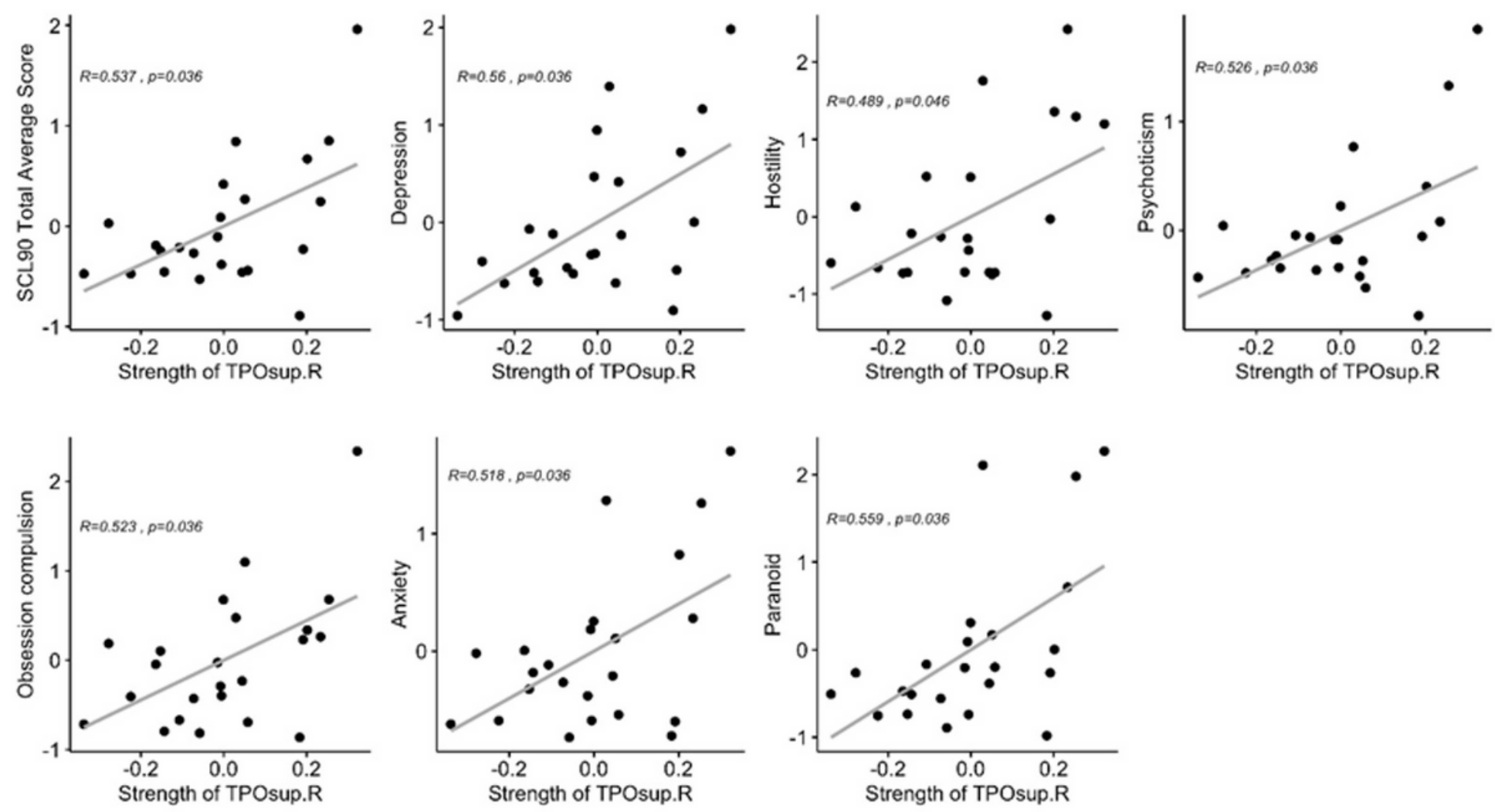

Figure 3

The correlations between the nodal strength in right superior temporal gyrus and SCL-90 scores in MAUD patients. Corrected by FDR. TPOsup. R: right superior temporal gyrus. 